\title{
Effectiveness of Emotional Intelligence Components on Social Adjustment and Social Intimacy of Women with Breast Cancer
}

\author{
Abed Mahdavi \\ Department of Psychology, Payame Noor University (PNU), PO BOX 19395 - 3697, Tehran, Iran \\ Corresponding Author. Email: abed_mahdavi@yahoo.com \\ Mohammad Ehsan Taghizadeh
}

Department of Psychology, Payame Noor University (PNU), PO BOX 19395 - 3697, Tehran, Iran

Soudabeh Isazadeh

Department of Psychology, Payame Noor University (PNU), PO BOX 19395 - 3697, Tehran, Iran

Ashraf Rezaei

Department of Psychology, Payame Noor University (PNU), PO BOX 19395 - 3697, Tehran, Iran

Somayeh Eghtedarnejad

Department of Psychology, Payame Noor University (PNU), PO BOX 19395 - 3697, Tehran, Iran

Shahrbanoo Sepehryeganeh

Department of Psychology, Payame Noor University (PNU), PO BOX 19395 - 3697, Tehran, Iran

\section{Doi:10.5901/mjss.2015.v6n6s6p59}

\section{Abstract}

The purpose of this study was to evaluate the effectiveness of the components of emotional intelligence on social adjustment and social intimacy of women with breast cancer. The study plan was practical with pre-test-post-test and control group. Statistical population consisted of all women with breast cancer having active file used health services of Shafa hospital of Khoram Abad. From the population, a sample of 40 women with cancer were selected through sampling method, and randomly divided into two experimental and control groups. Between the two tests, emotional intelligence training was performed for eight 2-hour sessions (once a week). The measurement tools of this study are: Bar-On emotional intelligence inventory, California test of social adjustment and Miller social intimacy scale. For the analysis of research data, descriptive and inferential statistics and SPSS statistical software were used. Results showed that the experimental group received the educational component of emotional intelligence compared with the control group in terms of social adjustment and social intimacy had significant differences. The results of this study can be used to enhance social adjustment and interpersonal intimacy of patients with breast cancer and also emotional and mental health services (emotional) can be provided to the department of clinical population as a non-pharmacologic cost effective treatment.

Keywords: Education of emotional component, Social adjustment and social intimacy and Breast cancer

\section{Introduction}

Cancer is an incurable disease that despite improvements in diagnosis and treatment is the reminder of the pain, limitations, deformity and death and according to World Health Organization statistics, the cancer is still define as a global disease (Jones and Bartlett, 2004). Chronic diseases like "Cancer" affect patients, families and other persons in relation with patient. Cancer causes a significant imbalance in the patient and her family and brings a set of new challenges for both. At least, ordinary daily life would change; for this reason, they try to find a compromise with the disease and respond to the demands of the threat (Awadallah, 2006). Among cancer patients, intimate relationships and receive support from others, acts as a shield against negative consequences and treatment, so establishes a strong relationship 
with the patient's psychological functioning (Helgeson and Cohen, 1996). The term "emotional intelligence" opened a new window in psychology. For The first time the term emotional intelligence were observed in academic articles of Salovey and Mayer (1993) (Michaeli and Emamzadeh, 2008). Emotional intelligence in recent decades, in addition to psychologists and psychiatrists has attracted public attention. There are two main conceptual idea of "emotional intelligence" that within each, different theoretical models have emerged. One of these theories is the theory of capability where El is the kind of cognitive ability or intelligence including skills related to emotional information processing (Van Roy et al, 2005). From this perspective, emotional intelligence is as the following: Person's capacity to reason about emotions and using them for thinking. This capacity includes particularly true capabilities to receive excitement, access to the emotions and renewing them aiming to facilitate thinking, understanding emotions, knowledge of emotion and to reflectively regulate emotions to enhance and improvement of emotional intelligence (Meyer et al, 2004). Studies have shown that emotional intelligence more than the intelligence quotient (IQ) predicts success person's life. People who are emotionally competent have better social skills, more ability to solve conflicts and stable long term relationships (Meyer, 1993). El has social, cognitive and biological advantages. Researches has shown that people with high emotional intelligence, have lower levels of stress hormones and other indicators of emotional arousal. Emotionally competent children are better able to focus more on the problem and use their problem solving skills that will enhance their cognitive abilities. One of the major models of emotional intelligence is 'Bar-on' model which considered as a base of study in this research. He has stated that his main goal was to develop a model of answering the question of why some people are more successful than others in life are. Hence with the study of theories and research in psychology, attempts to discover those characteristics, that are associated with success in everyday life. Bar-on (2006) considered social-emotional intelligence as a combination of competencies, skills and a facilitator that can effect on intelligent behavior. He discussed this concept includes aspects of emotional, personal and social intelligence. According to this view, people with high emotional intelligence, effectively understand themselves and others, can establish a good relationship with others and are able to adapt and deal appropriately with their immediate environment (Winters et al, 2004). Bar-on (2006) in a recent review of his model has called the recent concept as "social-emotional intelligence". From this perspective, socialemotional intelligence is the mediocrity of skills, competencies and of social and emotional and facilitator that specifies how efficiently and effectively we understand and express ourselves, how understand people and communicate with them and finally, how do we deal with the problems of everyday life. Bar-on generally believed that El has five components: 1Interpersonal skills 2- Interpersonal skills 3- Adapting skills 4- Inhibition of stress skills 5- General creation skills

Social adjustment is a relative concept, because of different cultures and beliefs in different societies. For example, if a particular behavior is considered normal and friendly in a Muslim country; but in another country is believed to be maladaptive. Social adjustment includes compatibility of individuals with their social environment that this may be achieved by changing themselves or the environment.

Emotional adjustment is good mental health, life and personal satisfaction and coordination between feelings and activities and thoughts. In other words, emotional adjustment means the mechanisms by which the person becomes emotionally stable. Social and emotional capabilities and competencies are influencing factors on academic adjustment (Mousavi, Lotfi, Akbari and Safavi, 2009). Intimacy is a sense of proximity, similarity, and the personal relationship of love and affection with others and requires in-depth knowledge and understanding of another person in order to express thoughts and feelings, which are used as a sources of similarity and proximity. Intimacy is an iterative process and includes interrelated aspects. The orientation of this process is knowledge, understanding, acceptance and empathy with the feelings of another person, recognition and acceptance of his views. Intimacy is not only a wish or hope, but also is an essential and broad concept that includes the disclosure, sexual contact and emotional, physical and rational closeness. With the loss of intimacy, one of a marriage rings disappears. Bagarozzi, consider intimacy including emotional, psychological, intellectual, sexual, physical, intellectual, aesthetic, social and recreational intimacy dimensions. The intensity of intimacy and its nine dimensions in each person is different from another one (Bagarozzi, 2001).

\section{Methodology}

The present study was practical and a quasi-experimental one with pre-test - post-test with control group. Population in this study was all women with breast cancer having active file that use health services of Shafa hospital of Khoram Abad. From this population, a sample size consisted of 40 women with cancer participated in the study through sampling method and randomly assigned to experimental and control groups. Between two tests, training components of emotional intelligence has done for eight 2-hour sessions (once a week). The measurement tools of this study are: emotional intelligence inventory of Bar-on, California test of social adjustment and Miller social intimacy scale. For the analysis of research data, descriptive and inferential statistics and SPSS statistical software were used. 


\subsection{Research Tools}

A- Bar-on emotional intelligence inventory: this questionnaire that was developed by the Bar-on (2006) has five component of "Interpersonal" skills (including sub-components of self-respect, self-awareness of emotional, Daring Interrupt, independence and self-actualization) "Intrapersonal "skills (Including sub-components of empathy, social responsibility, and interpersonal relationships) "Stress Management"(Including sub-components of stress tolerance and impulse inhibition), "Adaptation" (including reality testing, flexibility and problem solving) and the "general mood" (including sub-components of optimism and happiness) (Bar-on, 2006). In this study, normalized version of Samoei (2003) on dormitory students were used that through factor analysis appropriateness of the questions were examined, that the 90 items remained after the removal of the inappropriate questions. The coefficient of internal consistency, with Cronbach's alpha 0.93 and taking advantages of break-up was 0.98 . In this study the Cronbach's alpha of reliability was obtained 0.77 . Answering this test is a Likert five degrees.

B- Social adjustment inventory of California: The questionnaire was developed and released by Sorep, Clark \& Tick and in 1953 has been revised (Khodayarifard, 2004). The test is consists of two major parts of "self-suitability" and "social adjustment". In this study, only 90 items of social adjustment has been used. This test has six components as follows: 1- social structures 2- social skills 3- antisocial tendencies 4- family ties 5- educational relations 6- social relations.

The internal consistency of the subjects using two halves method of the Spearman method for the subscales of social adjustment is reported $(\alpha=0.87)$ to $(\alpha=0.90)$. Indicating that all of the following on scale six questions have appropriate internal consistency. In the study of Khodayari \& Fard et al (2006) Cronbach's alpha for the total score was $\alpha=0.98$. In this study, reliability of the questionnaire through Cronbach's alpha was obtained 0.87 .

C: Miller Social Intimacy Scale: This tool has been developed by Lefcourt \& Miller (1982). That scale of questions was created through organized interviews in which participants searched and discussed on the theme of intimacy in their relationships, including relationships with friends, acquaintances and family members. The scale included two groups of questions that the first six questions are aiming to describe the frequency of intimacy and 11 others have been devoted to the experienced intimacy of current time. Lefcourt \& Miller (1982) have been reported Cronbach's alpha coefficient of the questionnaire in different performances, between 0.86 to 0.91 and have been reported reliability coefficient using retest method, 0.84 (at an interval of more than two months) and 0.96 (with an interval of more than a month). In this study the Cronbach's alpha reliability of this scale has obtained 0.86. Answering questions is based on a Likert scale of 10.

\subsection{Components of emotional intelligence training program}

In this study the education component of, "Hatami Emotional Intelligence" program (2008) was used. After the pre-test, subjects were divided into experimental and control groups. It is noteworthy that terms of emotional intelligence training programs for both experimental and control groups were similar. In the next step participants in the experimental group participated in 8 sessions and received extra training. Style of sessions run as follows:

Style of the components of emotional intelligence training program in 8 sessions:

Session 1: Introduction of group members expressed purpose of medical treatment, education, definitions relating to breast cancer, definitions of intimacy and social adjustment

Session 2: Discussion of "emotional intelligence" and its components

Session 3: Understanding the concept of "Self-regulation of emotion."

Session 4: "Emotional self-control."

Session 5: "Emotional self-motivation."

Session 6: "Purification of emotions."

Session 7: "self-affections expressiveness"

Session 8: "self-emotional expressiveness" which aims imagery from the beginning to the end of the training session and the test was run.

\section{Findings}

After the implementation of the curriculum and scoring, data obtained from subjects was analyzed using statistical methods of mean, standard deviation, t-test and SPSS software. 
Table 1. Mean and standard deviation scores on emotional intelligence test of two control and experimental groups at pretest and posttest

\begin{tabular}{|l|l|c|c|c|c|}
\hline Group indicators & Test & Mean & Standard deviation & Minimum scores & Maximum scores \\
\hline \multirow{2}{*}{ Experimental } & pre-test & 320.9 & 44.1 & 184 & 344 \\
\cline { 2 - 6 } & post-test & 341.44 & 34.11 & 244 & 398 \\
\hline \multirow{2}{*}{ Control } & pre-test & 338.91 & 39.7 & 271 & 422 \\
\cline { 2 - 6 } & post-test & 343.25 & 36.25 & 278 & 411 \\
\hline
\end{tabular}

The results mentioned in table 1 shows that the mean (M:341.44) and standard deviation (SD:34.11) of experimental group in post-test scores is greater than the mean (M:320.90) and standard deviation (SD:44.10) of this group's pre-test scores in El. This result suggests that El of experimental group increased in post-test. However, the mean of pre-test and post-test scores of control group has not changed much.

Table 2. The mean and standard deviation of social adjustment scores of pre-test in both control and experimental groups

\begin{tabular}{|l|l|c|c|c|c|}
\hline Group indicators & Test & Mean & Standard deviation & Minimum scores & Maximum scores \\
\hline \multirow{2}{*}{ Experimental } & pre-test & 60.51 & 7.24 & 41 & 72 \\
\cline { 2 - 6 } & post-test & 65.3 & 5.84 & 50 & 77 \\
\hline \multirow{2}{*}{ Control } & pre-test & 57.74 & 7.4 & 46 & 68 \\
\cline { 2 - 6 } & post-test & 59.66 & 7.03 & 48 & 71 \\
\hline
\end{tabular}

Table 3. Mean and standard deviation of social adjustment dimensions in the pre-test and post-test scores in both control and experimental groups

\begin{tabular}{|c|c|c|c|c|c|c|c|c|c|}
\hline \begin{tabular}{|l|} 
Group \\
Indicators \\
\end{tabular} & & Pre-tes & & & & & Post-te & & \\
\hline Variables & & 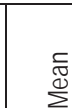 & 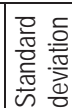 & 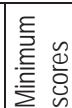 & 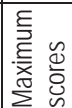 & 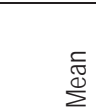 & 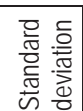 & 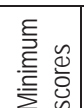 & 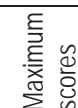 \\
\hline Social Structure & Experimental & 14.54 & 1.28 & 11 & 16 & 15.36 & 0.88 & 13 & 16 \\
\hline poctal siructure & Control & 12.91 & 2.34 & 9 & 16 & 13.27 & 1.94 & 10 & 16 \\
\hline Coninl crillr & Experimental & 11.16 & 2.4 & 7 & 15 & 12.26 & 1.89 & 9 & 16 \\
\hline |SOClal SKIIIS & \begin{tabular}{|l|} 
Control \\
\end{tabular} & 10.35 & 2.75 & 4 & 14 & 10.85 & 2.6 & 6 & 15 \\
\hline & Experimental & 10.86 & 1.6 & 7 & 13 & 11.81 & 1.33 & 9 & 14 \\
\hline |Antl-Soclal I endencles & \begin{tabular}{|l|} 
Control \\
\end{tabular} & 11 & 2.09 & 7 & 14 & 11.3 & 2.23 & 8 & 15 \\
\hline $\mathrm{F}_{2}$ & Experimental & 11.56 & 2.58 & 3 & 15 & 12.265 & 2.4 & 5 & 16 \\
\hline Irc & Control & 11.1 & 2.13 & 8 & 15 & 12.27 & 2.21 & 8 & 15 \\
\hline Fducational Relation & Experimental & 9.71 & 2.49 & 3 & 13 & 10.36 & 2.09 & 6 & 14 \\
\hline |Educational Relations & Control & 8.7 & 1.73 & 4 & 11 & 9.16 & 2.04 & 5 & 13 \\
\hline & Experimental & 9.76 & 2.55 & 4 & 15 & 10.36 & 2.53 & 5 & 16 \\
\hline |Soclal Relat & Control & 10 & 2.21 & 7 & 15 & 10.16 & 2.21 & 7 & 15 \\
\hline
\end{tabular}

Results in table 3 shows that the mean scores of experimental group in post-test for social adjustment dimensions is greater than mean scores of pre-test in this group. This result indicates that all dimensions of social adjustment increased in post-test. It also shows that Mean and standard deviation of post-test scores in social adjustment dimensions of control group Compared to the Mean and standard deviation of pre-test scores has not changed. This implies that the dimensions level of social adjustment in control group in post-test did not increase much. The data in table 3 shows the mean scores of social adjustment in experimental compared to the pre-test scores increased for this group, while the mean scores of social adjustment dimensions in post-test of control group compared to pre-test has not increased much. 
Table 4. Mean and standard deviation of social intimacy in post-test of both control and experimental groups

\begin{tabular}{|l|l|c|c|c|c|}
\hline Group Indicators & Test & Mean & Standard Deviation & Minimum Scores & Maximum Scores \\
\hline \multirow{2}{*}{ Experimental } & pre-test & 134.96 & 20.16 & 78 & 157 \\
\cline { 2 - 6 } & post-test & 137.06 & 18.61 & 80 & 154 \\
\hline \multirow{2}{*}{ Control } & pre-test & 136.8 & 18.96 & 89 & 157 \\
\cline { 2 - 6 } & post-test & 137 & 18.68 & 90 & 156 \\
\hline
\end{tabular}

Table 4 shows mean, standard deviation, maximum and minimum scores of social intimacy in pre-test and post-test of both control and experimental groups. Results of table 4 shows that the mean $(M=137.06)$ and $S D(S D=18.61)$ of posttest scores in experimental group is greater than mean $(M=134.96)$ and standard deviation (SD:20.16) of pre-test in this group in term of social intimacy. These results indicate that the amount of social intimacy of experimental group increased. However, mean and standard deviation of control group in post-test and pre-test had little change and indicate that the amount of social intimacy of control group in post-test has not significant increase.

Table 5. Mean and standard deviation of social intimacy in post-test of both control and experimental groups

\begin{tabular}{|l|l|c|c|c|c|}
\hline Group Indicators & Test & Mean & Standard Deviation & Minimum Scores & Maximum Scores \\
\hline \multirow{2}{*}{ Experimental } & pre-test & 133.99 & 20.17 & 78 & 156 \\
\cline { 2 - 6 } & post-test & 136.09 & 18.66 & 80 & 153 \\
\hline \multirow{2}{*}{ Control } & pre-test & 135.7 & 18.99 & 89 & 152 \\
\cline { 2 - 6 } & post-test & 136 & 18.71 & 89 & 152 \\
\hline
\end{tabular}

Table 6. T-test to compare increased scores of groups in emotional intelligence variable

\begin{tabular}{|l|c|c|c|c|c|c|}
\hline Variables & $\mathrm{T}$ & & Significance Level & Mean Differences & Effect Measure & Test Power \\
\hline Emotional intelligence & 6.33 & 27.8 & 0.001 & 20.48 & 0.49 & 0.96 \\
\hline
\end{tabular}

Table 7. T-test to compare increased scores of groups in social adjustment dimensions variable

\begin{tabular}{|l|c|c|c|c|c|c|}
\hline Variables & $\mathrm{T}$ & Degrees of freedom & significance level & mean differences & effect measure & test power \\
\hline Social Structure & -1.6 & 38 & 0.13 & -0.5 & 0.01 & 0.82 \\
\hline Social Skills & 2.14 & 38 & 0.04 & -0.8 & 0.39 & 0.94 \\
\hline Anti-social Tendencies & -3.09 & 38 & 0.004 & -1.86 & 0.43 & 0.95 \\
\hline Family Ties & 1.04 & 38 & 0.34 & -0.32 & 0.09 & 0.84 \\
\hline Educational Relations & 0.5 & 38 & 0.64 & -0.17 & 0.07 & 0.86 \\
\hline Social Relations & 2.12 & 38 & 0.043 & -0.47 & 0.34 & 0.91 \\
\hline
\end{tabular}

Table 7 shows that mean differences in experimental and control groups in dimensions of social skills $(P=0.04)$, antisocial tendencies $(P=0.004)$ and social relations $(P=0.043)$ is significant in the level of $P>0.05$. Hence, we can conclude that the average of social adjustment dimensions of experimental group in two dimensions of social skills and social relationships is significantly more and in dimension of anti-social tendencies is less than the control group. On this basis, we can say that learning, increase social skills and social relationships and significantly decrease anti-social tendencies. Effect size of $0.39,0.43$ and 0.34 also shows that for 39,43 and 34 percent of the difference between experimental and control groups in term of social skills, anti-social tendencies and social relations is related to the effects of El components training.

Table 8. T-test for comparison of groups in social intimacy (pretest-posttest difference scores)

\begin{tabular}{|l|c|c|c|c|c|c|}
\hline Variables & $\mathrm{T}$ & Degrees of freedom & significance level & mean differences & effect measure & test power \\
\hline Emotional Intelligence & 3.34 & 38 & -0.003 & -1.88 & 0.36 & 0.91 \\
\hline
\end{tabular}

As you seen in Table 8, average of increased scores in social intimacy in experimental group is significantly more than control group $(\mathrm{P}=0.003)$. Therefore, training of emotional intelligence components increased social intimacy. The effect sizes also shows that 36 percent of the difference between experimental and control groups in social intimacy is related 
to the training effects. Statistical power is equal to 0.91 that indicates test accuracy in detecting differences is 91 percent. Totally, independent t-test results show that training El components in increasing total El, total social adjustment, social relation and skills, decreasing anti-social tendencies and increasing social intimacy was significantly effective and useful.

\section{Conclusion}

In today's world, more than anything, adjustment and establishing a positive and close relationship, is essential whether at work or in the family. Research suggests that taking advantages of emotional intelligence and proper and on time education leads to better compliance and provides sustain positive relationship. According to the results obtained, there were significant differences between groups in the social adjustment. The impact of education on social adjustment can be explained by reasons such as: "Social adjustment" is defined as a process of adaptation of the individual to society as a reflection of human interaction with other people. Referring to that emotions and feelings of the individual, determines the degree of compliance (Pourafkari, 2001); No doubt the science of emotions and affection, how to control and manage them, plays significant role in creating consistency efficient, effective and appropriate with social status. The results also showed that between both control and experimental groups in dimension of social adjustment, there are significant differences in three dimensions of "social skills", "anti-social" and "social interaction" and there was no significant difference in other dimensions. In relation to the effects of training the dimensions of emotional intelligence on social adjustment can be said: social skills include interest to people, helping them and having good behavior with a stranger. An anti-social tendency includes tendencies of hurting others, the desire to fight and banish. A social relation includes intercourse with relatives, friends and neighbors, having good social relationships, positive emotion and pride of community activities and having patience with the familiar and the strange. Other findings from the research is that there are significant differences between the two groups (experimental and control) in term of "social intimacy". Given that social intimacy is one's desire to have a supportive and loving relationship without losing its own; to give an explanation for this finding could be said: studies have shown that the ability to recognize others' feelings and emotional balance have a close relationship with the warm and friendly relations with others. It could be argued that emotional awareness and understanding of affection along with teaching and empowering self-control and emotional self-regulation can facilitate the individual in terms of establishment the close relations with others.

\section{References}

Bonakdary, N. (2005).Relationship between emotional intelligence of parents and social adjustment of children. MA thesis Tehran: Tehran University.

Pourafkari, N. (2000). Comprehensive dictionary of psychological psychiatry. Tehran: Contemporary Culture.

Hatami, H.R. (2008). Studying the effects of training components of emotional intelligence on self-esteem, self-concept on Basiji adolescent hardiness. PhD thesis, Tehran: Tabatabai University.

Hajari, S. (2006). Effectiveness of problem-solving training on social adjustment of patients with bipolar affective disorder. MA thesis, University of Isfahan.

Khodayarifard, M. (2004). The relationship between religious attitude and relationship between parents and children with social adjustment of veterans and ordinary children in Tehran. Journal of Psychology, winter, 8 (372-388).

Khodayarifard, M., Rahimi Nejad, A. and Abedini, Y. (2006). Study of factors influencing social adjustment of Shahed and non-Shahed students. Journal of Humanities and Social Sciences University of Shiraz, Number III, Fall.

Khosro Javid, M. (2002). Reliability and validity of emotional intelligence in adolescents shot, MS Thesis, Tehran: Tarbiat Modarres University.

Dehshir, Gh. (2003). Standardization of Emotional Quotient of Bar-on Inventory among students of Tehran University and its factor structure. Master thesis of Allameh Tabatabai University.

Samoei, R. (2003). Normalization of emotional intelligence test. Tehran: Sinai psychology institution

Farahani, H. and Arizi, H.R. (2005). Advanced research methods in the humanities. Esfahan: Publication of Jahad Daneshgahi.

Frqdany, A. (2004). The relationship between emotional intelligence and social adjustment of undergraduate students at Allameh Tabatabai University, MA thesis.

Cosby, Paul C. (2008), The foundations of research in behavioral science. Translation, Hamid Reza, Arizi, Farahani, Hojatollah. Tehran: Ravan publication.

Michaeli, F., and Emamzadeh, Z. (2008). Study the relationship between social-emotional intelligence and social adjustment of students with adaptive warrant compared with students without a warrant. Urmia University. Journal of Psychology, University of Tabriz.

Hooman, H.A. (1991). Statistical Inference in Behavioral Research. Diba publications.

Abraham, A., \& Verghese, A. (1986). Eysenck Personality Inventory and Bell's Adjustment Inventory. Indian Journal of Clinical Psychology 13, 125-126.

Adeyemo, D. A. (2005). The buffering effect of emotional intelligencon the adjustment of secondray school students in transition. 
Electronic Journal of Research in Educational Psychology. 6-3(2).

Bar-On, R. (2006). The Bar-On Model of Emotional-Social Intelligence (ESI). Psicothema.18, 13-25.

Brackett, M. A. etal. (2004). Emotional intelligence and its relation to everyday behavior. Personality and Individual Differences, 36, 6, 1387-1402.

Chickering, A. W. \& Schlossberg, N. K. (1995). Getting the most out of college. Boston: Allyn and Baccon.

Ciarrochi, J., \& Scott, G. (2006). The link between emotional competence and well-being: Alongitudinal study. British Journal of Guidence \& Counselling. 34, $231-243$.

Crick, A. T. (2002). Emotional intelligence, social competence and success in high school students. Unpublished master's thesis, western Kentucky University, Bowling Green

Dhingra, R., Manhas, S., \& Thakur, N. (2005). Estabilishing connectivity of emotional quotient (EQ), spiritual quotient whith social adjustment: A study of Kashmiri Migrant Woman. J. Hum. Ecol. 18 (4), 313-317.

Engelberg, E \& Sjoberg, L. (2004). Emotional intelligence, affect intensity and social adjustment. Journal of Personality and Individual Differences. 37: 533-542.

Erikson, E. H. (1975). Life history and the historical moment. New York: Norton. Marquez, P. G-O., Martin, R. P., \& Brackett, M. C. (2006). Relating emotional intelligence to social competence and academic achievement in high school Students. Psicothema. $18,118-123$.

Mayer, J. D., \& Salovey, P. (1997). What is emotional intelligence? (PP 3-31). New York: Basic Books.

Mayer, J. D., \& Salovey, P. (1993). The intelligence of emotional intelligence. Intelligence 17 (4): 433-442.

Mayer, J. D., Salovey, P., \& Caruso, D. (2004). Emotional intelligence: Theory, findings and implications. Psychological Inquiry, 15 (3), 197-215.

Miller, R. S., \& Lefcourt, H. M. (1982). The assessment of social intimacy. Journal of Personality Assessment, 46(5), 514-518.

Oxford Dictionary of Psychology (2002). Linda. J. Durfee in Reference \& User Services Quarterly, 41 (3).

Parker, J. D. A. etal. (2004). Emotional intelligence and academic success: Examining the transition from hig school to university. Personality and individual Difference, 36, (1), 163-172.

Pascarella, E. T., \& Terenzini, P. T. (1995). The impact of college on students: Myths, rational myths, and some other things that may not betrue. Canada Journal. 15, 26-23.

Petrides, K. V. \& Furnham, A. (2001). Trait emotional intelligence: Psychometric investigation with reference to established trait taxonomies. European Journal of Personality. 15, 425-448.

Petrides, K. V. etal. (2004). The role of trait emotional intelligence in academic performance and deviant behavior at school. Journal of Personality and Individual Differences, 36, (2), 277-293.

Ryff, C., \& Singer, B. (1998). The contours of positive human health, Psychological Inquiry, 9, 1-28.

Van Rooy, D. L. Alonso, A., \& Viswesvarn, C. (2004) Group differences in emotional intelligen scores. Theoretical and practical implications. Personality and Individual Differences, 38. 689-700

Winters, J., Clift, R. J. W., \& Dutton, D. G. (2004). An exploratory study of emotional intelligence and domestic abuse. Journal of Family Violence, 19(5), 255-267.

Mayer JD and Salovey P. The intelligence of emotional intelligence, intelligence, 1993; 17(4), 433-442.

Mousavi-Lotfi, M., Akbari, V. \& Safavi, M. (2009). Why Emotional Intelligence. Qum: Qum University of Medical Sciences Press.

Awadallah, M.S. (2006). Support for cancer patients: The Bahrain experience, Eastern Mediterranean Health Journal, 12, 5.

Helgeson, V. S., \& Cohen, S. (1996). Social support and adjustment to cancer: Reconciling descriptive, correlation, and intervention research. Health Psychology, 15, (2,) 135-148.

Jones and Bartlett. A cancer source book for nurses. 8th ed. Philadelphia: Lippincott, Williams and Wilkins; 2004.

Bagarozzi D. Enhancing intimacy in marriage. USA: Brunner-Routledge; 2001: 25-6. 